\title{
O IMPACTO DO CAPITALISMO NO PROCESSO DE TRABALHO E NO PAPEL DO ESTADO*
}

\author{
Vera Lúcia Martins
}

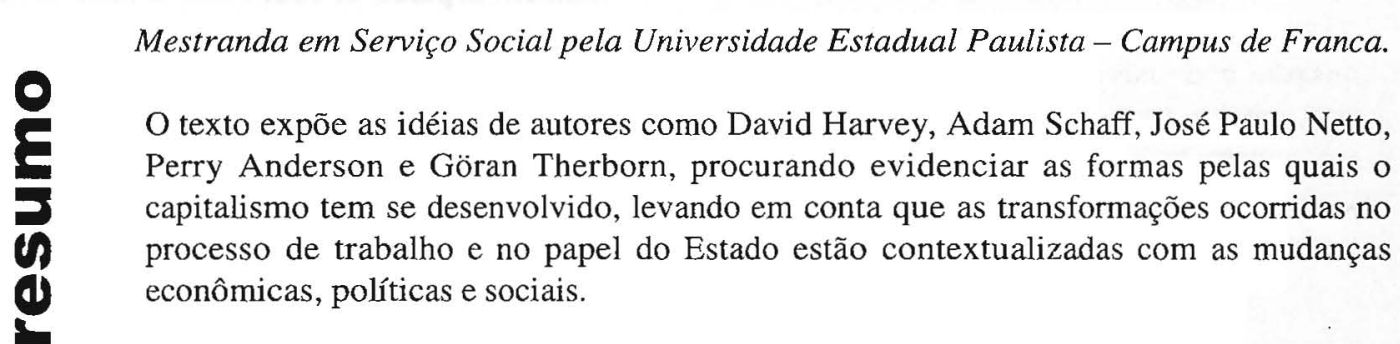

Palavras-chave: Estado; mercado; neoliberalismo; acumulação flexível.

$\mathbf{O}$ entendimento das novas formas que o capitalismo vem encontrando para continuar o seu desenvolvimento deve levar em conta o contexto no qual este se encontra assentado, ou seja, a globalização, o capital financeiro e as transformaçães tecnológicas.

Nesse sentido, buscar compreender os fundamentos históricos dessas transformações que estão ocorrendo nesse final de século e verificar a sua relação com as formas de produção e acumulação expressas hoje na chamada acumulação flexível constitui-se um dos objetivos desse trabalho; é objetivo, também, compreender as transformações que estão ocorrendo no processo do trabalho no mundo moderno e o novo tipo de relação que surge entre Estado, mercado e capital.

\section{AS CONCEPÇÕES SOBRE O MUNDO MODERNO}

\section{Fundamentos históricos da modernidade}

As transformações políticas, econômicas, sociais e até culturais que estão ocorrendo nesse final de século estão relacionadas com as formas de produção e acumulação vivenciadas num passado recente, cujas variações vão se expressar no chamado regime de acumulação flexível.
Para entender esse processo, necessário se faz contextualizar o que se caracteriza como modernidade e, em seguida, verificar a que se opõe a pós-modernidade.

O projeto de modernidade, segundo HARVEY (1993), surgiu durante o século XVIII. Na verdade foi um "esforço intelectual dos iluministas para desenvolver a ciência objetiva, a moralidade e a lei universais e a arte autônoma nos termos da própria lógica interna destas". (HARVEY, 1993, p.23)

O que se buscava era a emancipação humana, o enriquecimento da vida diária trazido com o acúmulo do conhecimento gerado pelo trabalho das pessoas.

A expectativa era que, com o domínio da ciência, a humanidade fosse liberta de todas as formas de escassez, de necessidades e de arbitrariedades das calamidades naturais. Isto é, esperava-se que a racionalidade nas organizações sociais superasse as práticas arbitrárias, desumanas, supersticiosas, religiosas e míticas e, portanto, a emancipação das tradições medievais trazendo a libertação e a liberdade individual.

O projeto modernizador dos iluministas, quando alcançado, traria a compreensão do mundo e do eu e o domínio e controle das forças naturais, o progresso moral, a justiça das instituições e até a felicidade dos seres humanos através das artes e das ciências.

Buscavam os iluministas a igualdade, a liberdade e a fé na inteligência humana. Era uma visão otimista, segundo Harvey. Na essência, o projeto iluminista buscava o controle e a organização do mundo de forma racional, através de uma única forma de sua representação.

\footnotetext{
* O texto é uma adaptação da monografia intitulada $O$ impacto das transformações do capitalismo no processo de trabalho e no papel do Estado, apresen tada como trabalho de conclusão do curso de Especialização em Sociologia e Sociologia da Educação, da UEL, em agosto de 1997, sob orientação do professor Ronaldo Baltar.
}

Rev. Mediações, Londrina, v. 4, n. 2, p. 51-57, jul./dez. 1999 
Entretanto, o pensamento dos iluministas sobre um único modo possível de representação começa a ruir, surgindo pensamentos que consideram "sistemas divergentes de representação", cuja reação pode ser vista no que alguns chamam de "sociedade pós-moderna".

\section{A sociedade pós-moderna}

As análises das mudanças que estão ocorrendo a partir dos anos 1970 nas práticas políticas, econômicas e culturais indicam que essas transformações estão relacionadas às novas formas como experimentamos o tempo e o espaço.

Segundo HARVEY (1993), essas transformações evidenciam uma relação, não necessariamente causal, entre as formas culturais pós-modernas e as formas mais flexíveis de acumulação do capital, ou seja, evidenciam um "novo ciclo", uma nova compreensão da questão espaço-tempo na organização capitalista.

Embora sem a pretensão de determinar se as mudanças que estão ocorrendo caracterizam de fato uma nova fase, a que muitos têm chamado de pós-moderna, acreditamos, no entanto, que essas transformações vão influenciar também as mudanças no processo de trabalho e no papel do Estado, visto que uma nova reorientação vem determinando as ações dos governantes, qual seja, a onda do neoliberalismo, da flexibilização do capital e da abertura de fronteiras, da quebra das barreiras políticas, econômicas e culturais para uma nova sociedade globalizada.

O mundo moderno, tido como positivista, tecnocêntrico e racionalista é geralmente identificado com a crença no progresso linear, nas verdades absolutas, no planejamento racional de ordens sociais ideais e com a padronização do conhecimento e da produção.

O pensamento pós-moderno, por sua vez, privilegia a heterogeneidade e a diferença como forças libertadoras na redefinição do discurso cultural. A fragmentação, a indeterminação e a intensa desconfiança de todos os discursos universais ou totalizantes são o marco do pensamento pós-moderno. O efêmero, o fragmentário, o descontínuo, o caótico são perfeitamente aceitos como características do pensamento pós-moderno e, mais, busca-se a diferença, não a uniformidade.

Os grandes esquemas interpretativos são colocados em xeque e percebe-se uma acentuada rejeição às metalinguagens, às metanarrativas, às metateorias como modelos explicativos/interpretativos através dos quais todas as coisas possam ser conectadas ou representadas.

Na cultura contemporânea o ecletismo abre espaço para a convivência das mais diferentes formas de manifestações políticas, religiosas e sociais:

"Ficção, fragmentação, colagem e ecletismo, todos infundidos de um sentido de efemeridade e de caos, são talvez os temas que dominam as atuais práticas da arquitetura e do projeto urbano. E, evidentemente, há aqui muita coisa em comum com práticas e pensamentos de muitos outros campos, como a arte, a literatura, a teoria social, a psicologia e a filosofia”. (HARVEY, 1993, p.96)

Nesse sentido, acredita-se ser possível verificar que a racionalidade da sociedade moderna "iluminou", sob muitos aspectos, a era das trevas do período medieval. Contudo, a crença no planejamento racional ideal, com a consequiente padronização do conhecimento e da produção, trouxe como legado uma sociedade tecnocêntrica, racionalista, e um culto à tecnologia e à ciência.

O mundo moderno deu à luz as mais eficientes formas de produção racionalizadas, incrementando no processo de trabalho, forças cada vez mais poderosas e eficientes para a maximização do lucro e otimização do tempo. Mas também deparou-se com a forma mais desumana de expropriação do trabalhador do seu processo produtivo.

Criou no seu interior o movimento de alienação, desagregação social e perda da identidade e da subjetividade humanas, que, presentemente, são agudizadas com as novas formas que o capital tem encontrado na busca pela aferição do lucro.

\section{AS TRANSFORMAÇÕES NO PRO- CESSO DE TRABALHO NO MUNDO}

\section{Contextualizando o processo de transfor- mação do trabalho}

O movimento do capital, ou seja, o impulso de realocação para locais mais vantajosos, revoluciona periodicamente a divisão territorial e internacional do trabalho, acrescentando à insegurança uma dimensão geográfica vital.

A transformação da experiência do espaço e do lugar é também acompanhada pela dimensão do tempo, na medida em que os capitalistas tentam reduzir o tempo de giro do seu capital "a um piscar de olhos".

Assim, a circulação do capital, incansável e eternamente em busca de novas formas de aumentar os seus ganhos, revoluciona, fragmenta e cria uma insegurança perpétua.

Mas, como coloca HARVEY (1993), para que o capital possa, de fato, efetivar os seus ganhos, uma vez que o capitalismo não se restringe apenas à produção e à troca no mercado, certas condições históricas, em especial a existência do trabalho assalariado, são necessárias antes da busca pelo lucro.

O trabalho - tempo socialmente gasto na produção de uma mercadoria - trabalho abstrato, apresenta-se como força de trabalho que, ao ser transformado em mercadoria, pode ser comprada e vendida desde que o trabalhador esteja desvinculado dos seus meios de produção, ficando apenas com a sua força de trabalho para vender:

"Os capitalistas, ao comprar a força de trabalho, tratam-na necessariamente em termos instrumentais. $\mathrm{O}$ 
capitalista dispõe do trabalho dos outros sem considerar necessariamente o que estes possam pensar, precisar ou sentir (...). Os capitalistas podem utilizar seus direitos de modo estratégico para impor todo tipo de condições ao trabalhador. Este último costuma estar alienado do produto, bem como da capacidade de realizar o valor do fruto de seus esforços esse valor é apropriado pelo capitalista como lucro". (HARVEY, 1993, p.101)

Assim, tanto o capital quanto o capitalista constituem-se em objetividade estruturante na correlação de forças, pois ambos têm mais poder de se concretizar e de se impor ao trabalhador, ficando este numa relação de subalternidade no contexto da exploração do trabalho pelo capital.

Disso resulta a fragmentação, a divisão do trabalho - com novas formas de organização e produção da mercadoria —, a alienação do trabalhador do seu trabalho e do seu resultado final - o produto acabado - e a desvinculação do trabalhador do processo produtivo.

Hoje, com a acumulação flexível, surge uma nova forma de organização e produção da mercadoria e do trabalho que, com o deslocamento mundial das empresas, passam a definir os seus preços conforme cada país e não com base na idéia localizada de empresa.

Nesse sentido, as revoluções tecnológicas tiveram o efeito de desmistificar os processos de produção e de criar a capacidade de liberar a sociedade da escassez e dos aspectos mais opressivos da necessidade imposta pela natureza. Esse, como diz Harvey, foi o lado bom da modernização capitalista.

Entretanto, a tecnologia mitificada, separada do ser e do fazer humanos, no capitalismo aparece, como algo neutro, à parte do social, vinculada à idéia de progresso, sendo considerada um fim em si mesma.

Dessa forma, ela pode levar ao interior das sociedades o agravamento do desemprego estrutural-tecnológico e à conseqüente sedimentação da exclusão e desagregação social de uma grande parcela populacional. E mais, a tecnologia pode levar o homem a olhá-la de forma alienada, não percebendo que também é fruto do trabalho coletivo, cultural.

Assim, as condições de modernização capitalista desenvolvimento especulativo; mudanças imprevisíveis nos métodos de produção e consumo (desejos e necessidades); mudança da experiência do espaço e do tempo - , bem como uma dinâmica de mudança social impelida pela crise, formam o que Harvey chama de contexto material que tem promovido o individualismo, a alienação, a fragmentação, a efemeridade, a inovação e a "destruição criativa". Do ponto de vista da nova organização da produção, isso pode ser exemplificado com a acumulação flexível.

\section{Acumulação flexível}

Em 1973, quando a aguda recessão abalou o quadro da aparente estabilidade do regime fordista, deixando claro que, desde anos anteriores, havia um enfraquecimento da demanda efetiva com uma consequiente queda da produtividade e da lucratividade corporativas, inicia-se o que se convencionou chamar de regime de acumulação flexível.

A rigidez do fordismo - rigidez de investimentos em sistema de produção em massa; rigidez no planejamento que presumia um crescimento estável em mercados de consumo invariantes; rigidez nos mercados e na alocação dos recursos e nos contratos de trabalho (especialmente no setor monopolista) - veio se confrontar com o sistema de acumulação flexível apoiada na flexibilidade dos processos de trabalho, dos mercados de trabalho, dos produtos e padrões de consumo.

Com a acumulação flexível surgem setores de produção inteiramente novos, novas maneiras de fornecimento de serviços financeiros, novos mercados, sobretudo taxas altamente intensificadas de inovação comercial, tecnológica e organizacional, envolvendo rápidas mudanças dos padrões de desenvolvimento desigual, criando um vasto movimento no emprego, no setor de serviços, bem como uma nova compreensāo do espaço/tempo no mundo capitalista. (cf. HARVEY, 1993)

No tocante ao trabalho organizado, este foi solapado pela reconstrução de focos de acumulação flexível em regiões que careciam de tradições industriais anteriores e pela reimportação, para os centros mais antigos, das normas e práticas regressivas estabelecidas nessas novas áreas.

A acumulação flexível implica níveis relativamente altos de desemprego estrutural, rápida destruição e reconstrução de habilidades, ganhos modestos (quando há) de salários reais e o retrocesso do poder sindical — uma das colunas políticas do regime fordista.

Há um visível enfraquecimento do poder sindical, o que permite aos patrões a imposição de regimes e contratos de trabalho mais flexíveis. A isso acresce a redução do emprego regular em favor do crescente uso do trabalho em tempo parcial, temporário ou subcontratado.

A atual transformação da estrutura do mercado de trabalho oportuniza ainda o ressurgimento e o florescimento de sistemas mais antigos de trabalho doméstico, artesanal, familiar (patriarcal) e paternalista ("padrinhos", "patronos"), como peças centrais e, não, como apêndices do sistema produtivo.

Vale destacar que, em função da crescente diminuição no mercado de trabalho, da absorção da mão-de-obra trabalhadora decorrente das políticas voltadas para a modernização da economia globalizada, há um aumento significativo no crescimento das economias "informais" em todos os países capitalistas avançados ou em processo de modernização, como tentativa de sobrevivência num sistema concorrencional injusto e desleal para com a parcela da população que vive do trabalho.

Quanto à produção de mercadorias, se no sistema fordista havia a chamada rigidez na produção e um consumo de massa, no regime de acumulação flexível a produção de mercadorias vai ser orientada para os pequenos lotes, para a produção "magra" (lean prodution), produção por demanda, por solicitação, o que sem dúvida vai atender a uma gama bem mais ampla da necessidade de mercado, muito embora a vida útil de um produto pós-fordista tenha se reduzido à 
metade, em especial os produtos como vestuário e eletroeletrônicos.

Na acumulação flexível, estreita-se a distância entre a produção e o consumo, fazendo com que o que é produzido seja orientado mais para a moda do que para as necessidades reais.

No novo regime de produção e acumulação cria-se a necessidade do consumidor através da oferta de um infinidade de produtos atraentes, acessíveis mas plenamente descartáveis, e estimula-se no consumidor a compra por impulso.

Nesse sentido, na atual situação, o capitalismo, a considerar esses indícios, está se tornando cada vez mais organizado, através da dispersão, da mobilidade e das respostas flexíveis no mercado de trabalho, nos processos de trabalho e nos mercados de consumo, tudo isso acompanhado por pesadas doses de inovação tecnológica, de produto e institucional.

Dessa forma, os resultados são claros, pois, se por um lado o desenvolvimento das forças produtivas libera o homem do esforço do trabalho físico e, às vezes, intelectual, por outro, exige que se encontre uma solução para os sérios problemas sociais advindos da eliminação crescente de postos de trabalho.

Problemas sociais esses que, com toda a certeza, os países considerados de Terceiro Mundo ou periféricos (como o Brasil) sentirão com maior agudeza.

Como afirma SCHAFF (1991), a influência da revolução industrial no mercado de trabalho, nos países industrializados, provocará o desemprego estrutural por influência da automação e da robotização, eliminando a mão-de-obra humana da produção e dos serviços. Nos países subdesenvolvidos, porém, esta influência provoca efeitos semelhantes, mas seu mecanismo é indireto, ou seja, os países industrializados, por consequiência da automação e robotização, reduzem seus investimentos no Terceiro Mundo e até mesmo retiram os investimentos já realizados.

Tal fenômeno pode ter como causa tanto a perda do interesse pela mão-de-obra barata dos países do Terceiro Mundo quanto o desestímulo para a exportação de capitais para esses países, ocasionado pela falta de competitividade dos produtos dos países subdesenvolvidos por falta de métodos avançados de industrialização.

Com base nesse raciocínio, os países considerados do Terceiro Mundo, se continuarem com os métodos tradicionais, como o uso da mão-de-obra barata, por exemplo, não terão competitividade no mercado, mas se se modernizarem, eliminarão a mão-de-obra, trazendo como conseqüência o agravamento do desemprego estrutural.

Contudo, nos países avançados, a economia capitalista e, em especial, a do período fordista, pode ser vista como a que melhor embasou, solidificou e sustentou um regime plenamente acabado, com taxas de crescimento econômico estáveis, melhoria nos padrões de vida e ascensão de indústrias com bases tecnológicas desenvolvidas. Mas essa expansão só foi possível devido ao reposicionamento por parte do Estado e à reorganização do capital e do trabalho.

Com a flexibilização dos processos de trabalho, dos mercados, dos produtos e do consumo, após a recessão de
1970, novos setores de produção, de serviços e de mercados foram criados, o que também levou o Estado a realinhar-se diante dessas transformações.

Mas esse realinhamento, no tempo presente, vem colocar-se em confronto com a política de proteção social, mais conhecida como Estado de Bem-Estar Social.

\section{AS MUUDANÇAS NO PAPEL DO ESTADO}

\section{O Estado de Bem-Estar Social e o neolibe- ralismo}

O Estado, ao atender as reivindicações dos setores do proletariado, adota uma política conhecida como bemestar social. Para tanto, amplia a sua estrutura administrativa, absorvendo trabalhadores numa tentativa de reduzir níveis de desemprego.

Segundo NETTO (1996), essa modalidade de intervenção do Estado decorre, primariamente, da demanda que o capitalismo tem de um vetor extra-econômico para assegurar seus objetivos estritamente econômicos.

Conforme o autor, isso significa que o Estado é capturado pela lógica do capital monopolista, tornando-se o seu Estado e, para que tenha condições de atuação, ele precisa legitimar-se politicamente através de instrumentos democráticos. Torna-se permeável às demandas e reivindicações da população, mas é constantemente tensionado tanto pelos conflitos sociais como pelas exigências monopólicas.

Vale ressaltar, no entanto, que, no Brasil, o EstadoProvidência ou de Bem-Estar Social nunca se efetivou de fato. Historicamente, o Estado brasileiro tem se pautado por uma relação de subserviência e entrelaçamento com o capital, resultando, no campo das políticas sociais públicas, numa subordinação aos interesses econômicos, impedindo, por exemplo, que a questão da pobreza receba o tratamento adequado e seja colocada na agenda do dia como um problema estrutural e, consequientemente, como uma questão social grave, pois resultante de um modo de produção voltado para a riqueza e para a criação de valor de troca - a mercadoria.

Dessa forma, tem-se que o Estado de Bem-Estar Social, nos países ricos, surge como uma tentativa de redistribuição de renda, no sentido de que promove e subsidia melhorias na qualidade de vida da população que, de outra forma, não seriam alcançadas dentro de um sistema produtor de mercadorias que por natureza é excludente e desagregador.

Esse Estado surge também como saída para as grandes crises econômico-sociais capitalistas, como foi a de 1929, que desarticulou mundialmente todos os níveis de produção burguesa, crise da superprodução de mercadorias, com a falência de centenas de fábricas, milhares de trabalhadores desempregados e perda de vultosos investimentos de capital.

Com isso, o Estado burguês cria mecanismos de intervenção que visam tanto a administrar os períodos de crise 
do mundo capitalista quanto a proporcionar condições para o desenvolvimento do capital.

Essas intervenções revelam-se diretamente quando o Estado age como empresário nos setores básicos, fornecendo aos monopólios, a baixo custo, energia e matérias-primas fundamentais, bem como a entrega de complexos construídos com fundos públicos.

Netto coloca que, indiretamente, a intervenção do Estado está relacionada com os investimentos públicos em meios de transporte e infra-estrutura, na preparação institucional da força de trabalho e nos gastos com investigação e pesquisa, além de atuar como administrador dos ciclos de crise.

Ocorre que, com a crise do mundo capitalista, a grande recessão de 1973, as idéias e os conceitos neoliberais ganharam força e se colocaram como respostas às raízes da crise, ou seja, ao

"poder excessivo e nefasto dos sindicatos e, de maneira mais geral, do movimento operário, que havia corroído as bases de acumulação capitalista com suas pressões reivindicativas sobre os salários e com sua pressão parasitária para que o Estado aumentasse cada vez mais os gastos sociais". (ANDERSON, 1996, p.10)

Essas críticas foram, na verdade, uma reação teórica e política veemente contra o Estado intervencionista e de Bem-Estar.

Para os neoliberais, a liberdade individual deve prevalecer e qualquer tipo de intervenção do Estado deve ser afastada; por isso, os programas sociais através da provisão de renda, bens e serviços pelo Estado vão se constituir ameaças aos interesses e liberdades individuais, inibindo a atividade e a concorrência privada e gerando indesejáveis extensões dos controles da burocracia.

Mas, segundo THERBORN (1996), o Estado de BemEstar, apesar de todos os ataques sofridos, veio a ser uma instituição sólida em cada sociedade avançada e moderna e, uma das razões, pelo menos na Europa ocidental e na América do Norte, foi que esse Estado chegou a ser uma instituição central na vida cotidiana de grande parte da população.

Dados estatísticos apontados pelo autor dão conta de que, nos Estados Unidos, a renda primária de mais ou menos $40 \%$ da população depende do setor público. Em países europeus o percentual pode chegar a $65 \%$, considerando aposentados, assalariados e outras formas de transferências públicas. Por isso, é possível afirmar que

“Teria havido mesmo um 'círculo virtuoso' entre a política econômica keynesiana e o Welfare State: aquela regula e estimula o crescimento econômico; este por sua vez, arrefece os conflitos sociais e permite a expansão de políticas de corte social que amenizam tensões e, no terceiro momento, potenciam a produção e a demanda efetiva". (DRAIBE \& HENRIQUE, 1988, p.55)

Mas, ao que tudo indica, o pano de fundo necessário para o conflito entre a política econômica e a política social foi a estagnação do crescimento econômico, a ascensão da inflação e o déficit público dos Estados. Junta-se a esse fato o entendimento neoliberal de que o Welfare State é uma estrutura perniciosa e corresponde a uma concepção perversa e falida do Estado.

Nesse sentido, para os neoliberais, os gastos sociais do Estado elevam os déficit públicos, penalizando assim a atividade produtiva e levando à inflação e ao desemprego. Argumentam ainda que o Estado, ao intervir através dos programas sociais, desestabiliza o funcionamento da economia. Os programas sociais, ao promover uma "igualdade perniciosa," ferem a ética do trabalho, levando ao desestímulo do trabalho e comprometendo o mecanismo de mercado.

Quanto à intervenção e regulação do Estado no campo político, entendem como uma ação autoritária, chegando mesmo às raias do totalitarismo.

Os excessivos programas sociais de proteção (seguro desemprego, pensões, aposentadorias, etc.) e de redistribuição, minam ou negam o maior incentivo ao trabalho - a necessidade —, sendo, dessa forma, perniciosos, pois geram a própria pobreza.

Portanto, a redução dos programas que dizem respeito aos benefícios, ao controle do acesso e de fraudes, à austeridade no fornecimento de bens e à privatização dos serviços é, entre outras, uma das soluções apontada pelos defensores do neoliberalismo.

"A intervenção do Estado deve estar orientada para tudo o que favoreça em empresas: menor controle, redução da tributação, principalmente sobre investimento e capital. (...) só assim haveria crescimento e o crescimento do setor privado é a melhor forma de combater a inflação. $O$ que melhor deveria fazer $o$ Estado então seria restringir-se a aumentar os lucros das empresas". (idem, p.58)

Assim sendo, o modelo Welfare State de proteção social e regulação econômica busca, nos dias atuais, a superação da crise, tornada evidente a partir de 1970.

No tocante às políticas sociais, o neoliberalismo propõe, em momentos de crise, o redirecionamento da política social com propostas de corte do gasto social, a desativação dos programas e a efetiva redução do seu papel nesse campo.

Isso implica reduzir a universalidade e os graus de abertura de muitos programas sociais, assistencializando - retirando do campo dos direitos sociais - muitos dos benefícios e privatizando, quando possível, a produção, a distribuição ou ambas as formas de provisão dos serviços sociais.

Vale ressaltar que, cada país, principalmente os de capitalismo avançado, a partir de suas peculiaridades econômicas e políticas, implantou, a seu modo, a ideologia neoliberal nos anos 80 e, conforme as suas próprias convicções, implementou o programa neoliberal de forma a atender as suas prioridades de governo.

Todavia, a onda neoliberal dos países de capitalismo tardio ou atrasado, que nem sequer implantaram a política do Estado de Bem-Estar Social de forma ampla e eficaz, ainda está por se fazer sentir em todas as suas dimensões: econômica, social, política e ideológica. 
Como afirma ANDERSON (1996), o neoliberalismo ainda é um movimento inacabado e qualquer balanço é provisório. Apenas nos países de capitalismo mais avançado do mundo é que é possível verificar os resultados políticos, econômicos, sociais e ideológicos, mas, mesmo assim, resultados positivos apenas do ponto de vista neoliberal e no que diz respeito aos aspectos sociais: sociedades mais desiguais.

\section{Mobilidade do capital - mais rápido em relação ao Estado}

Para THERBORN (1996), as instituições maiores das economias modernas, constituídas pelos Estados (o poder político, que pode ser autoritário ou democrático), pelas empresas (o poder empresarial, que é o poder de mando e também de negociação) e pelo sistema de mercados (o poder da competição), alternaram entre si, na história do capitalismo mundial, momentos de ascensão e declínio.

Com base na análise que este autor levanta, durante o período de expansão dos cartéis, das alianças entre as grandes empresas monopólicas chamadas de capitalismo organizado, as empresas e os Estados eram relativamente fortes. Entretanto, após a Segunda Guerra Mundial, os mercados, em especial o de mercadorias, começaram a se estender com uma nova abertura do comércio mundial sob a hegemonia e a pressão do modelo norte-americano e, com a sua expansão, criou-se um aumento da competição, devido, empiricamente, ao crescimento do comércio mundial em relação à produção, criando o fortalecimento dos mercados em relação às empresas.

Após a Segunda Guerra Mundial, com a difusão dos Estados sociais e com a industrialização, em especial, na América Latina, subsidiada pela intervenção estatal, o Estado se fortaleceu e cresceu não só na Europa ocidental, como também no restante do mundo.

Entretanto, nas décadas de 70 e 80, segundo Therborn, houve uma mudança radical no desenvolvimento do capitalismo, que se refletiu nas relações entre os mercados e as empresas e entre os Estados e os mercados.

Após o período de glória da industrialização nos países avançados, no fim dos anos 60 , deu-se início ao processo de desindustrialização, com a chegada da economia pósindustrial, alterando a relação entre mercado e empresa, o que levou a uma transformação na constituição da sociedade moderna.

A flexibilidade no processo de produção, graças à introdução de inovações tecnológicas de manejo eletrônico e computadorizado fez com que as relações de força e de poder entre as empresas individuais e o poder de mercado se modificassem.

Mas o mais dramático elemento que interferiu no novo crescimento do mercado foi a enorme expansão dos mercados financeiros internacionais, que começou com o déficit dos Estados Unidos financiando a guerra do Vietnã. "Com as recentes inovações tecnológicas, tanto de negócios quanto de jogos financeiros, estes mercados chegaram a ser extraordinariamente grandes em sua riqueza e em seus recursos". (THERBORN, 1996, p.44)
Essa expansão dos mercados financeiros tem grande importância, na medida em que esses mercados se tornam muito competitivos, possuindo, eles mesmos a sua própria dinâmica, que, por sua vez, se reflete na mudança produzida nas relações entre os mercados e os Estados.

Dessa forma, os Estados nacionais podem chegar a se tornar até menores em relação a este novo mercado financeiro mundial, ao mesmo tempo que passam a depender da confiança destes mercados para implementar grande parte das políticas estatais.

Esses mercados, gerando mais capital do que o próprio Estado, estimulam as privatizações, que, para além dos motivos puramente políticos e ideológicos, indicam uma mudança nas relações de força entre os Estados e os mercados.

Para Therborn, esse processo faz parte de uma dinâmica de transformação histórica nas relações entre empresas, Estados e mercados, bem como as crises cíclicas, constituindo o ritmo normal da vida do capitalismo.

Assim, o capitalismo, na visão do autor em questão, não se encontra desorganizado e não enfrenta uma contradição econômica estrutural, mas, sim, uma contradição ideológica mais do que econômica.

A crise manifesta-se na supressão de postos de empregos, no empobrecimento de parcelas cada vez maiores da população e, por fim, na exclusão social de uma grande parte da população; nisso está a sua contradição sociológica.

\section{CONSIDERAÇÕES FINAIS}

Conquanto os iluministas buscassem a emancipação do homem no que diz respeito à escassez, às necessidades e às calamidades naturais e acreditassem também na liberdade e na inteligência humanas através da organização racional do mundo, essa busca encerra em si uma pretensão cuja limitação a própria história tem incumbido de mostrar.

A tarefa que o homem se propõe tem se revelado, no mais das vezes, incapaz de dar conta da infinitude dos problemas advindos da busca de novas descobertas que, em tese, promovam o bem-estare a felicidade dos pessoas.

O discurso que notadamente tem marcado as ciências de um modo geral, a limitação dos grandes modelos teórico-interpretativos, bem como a reação a esses modelos, mostram-nos que as transformações a que estamos assistindo na atualidade nos trazem mais dúvidas do que respostas.

O convívio com o efêmero, com o fragmentário e com a diferença já não causa espanto. A unidade, a forma e a harmonia já não são necessárias para o equilíbrio nas relações, ao contrário, a estrutura do sentimento pós-moderno tem como característica a antítese de todos os modelos e formas interpretativas consideradas de larga escala e de aplicação pretensamente universal.

Dessa forma, entender o mundo no qual vivemos e compreender como os processos de mudanças afetam as relações econômicas, políticas e sociais exige um esforço que vai além da compreensão estrutural. Exige o entendimento 
de como essas relações vão se entrelaçando e se autodeterminando, criando uma rede de interligações onde fica difícil precisar a influência de uma sobre a outra.

Nesse sentido, a compreensão das mudanças ocorridas no processo de trabalho e no papel do Estado tem como pano de fundo todas essas transformações, que, no seu curso, têm se mostrado surpreendentes.

Já não é suficiente entender que as relações sociais estão mediadas por relações mais concretas e históricas no processo de exploração entre capital e trabalho. Tampouco é suficiente saber que o capitalismo, na ânsia por aferir maiores lucros, criou o internacionalismo e a insegurança, revolucionando a divisão territorial e internacional do trabalho.

Também já não é suficiente a consciência da alienação do trabalhador do seu processo produtivo nem da intensificação e expropriação do seu saber pelas principais formas revolucionárias de produção vivenciadas até hoje, quais sejam, o fordismo, o taylorismo e o toyotismo.

O poder sindical, que em tempos idos erguia a bandeira de salários mais dignos para o trabalhador, de conquistas trabalhistas e sociais que garantissem a integridade desse trabalhador e a sua própria identidade, hoje encontrase visivelmente enfraquecido, dobrado, pela mão mais do que visível do Estado e da onda neoliberal.

Hoje, a própria capacidade de gerenciamento do Estado é colocada em xeque, o que permite o ressurgimento e acirramento das críticas ao Estado intervencionista.

Nesse contexto, as idéias neoliberais ganharam força, exigindo que os governos redimensionassem suas políticas econômicas e sociais através de incentivos fiscais, privatizações e cortes em programas sociais de proteção ao trabalhador, entre outros.

Contudo, as mudanças que estão ocorrendo na economia, na política e no papel do Estado, se consideradas como novas formas que a acumulação capitalista tem encontrado para continuar se expandindo, devem, contudo, ser vistas como um processo e, como tal, inacabado e do qual ninguém tem ainda a última palavra.

Nesse sentido, ainda que o modelo do Estado de BemEstar Social esteja em crise, conclusões positivas sobre o novo modelo teórico, ideológico e doutrinário do neoliberalismo ainda carecem de comprovação prática. O que se sabe, com base em exemplos de outros países, é que a hegemonia do programa neoliberal já está sendo sacudida pelos seus aspectos negativos - sociedades mais desiguais.

Se o entrelaçamento entre os mercados, as grandes empresas e o Estado no período de expansão dos cartéis se diluiu e se modificou com a chegada das inovações tecnológicas, eletrônicas, computadorizadas e com a expansão dos mercados financeiros internacionais, a nova dinâmica competitiva desses mercados vai interferir nas relações entre os mercados e os Estados, indicando mudanças de ordem ideológica, política, econômica e, sobretudo, de forças entre Estado e mercado.

Assim, o metamorfoseamento dessas relações, para além de uma dinâmica de transformação histórica e natural, dentro do capitalismo, dá indícios de uma grande contradição, não apenas sociológica, mas de ordem prática e concreta.
A partir do momento em que o mercado financeiro mundial se torna mais forte e capaz de influenciar as políticas estatais, deixando o Estado à mercê de sua confiança, uma nova ordem mundial pode ser vislumbrada. No limite, pode excluir e manter à deriva do mercado de trabalho uma parcela cada vez maior da população.

\section{REFERÊNCIAS BIBLIOGRÁFICAS}

ANDERSON, Perry. "Balanço do neoliberalismo". In: SADER, E. Pósneoliberalismo: as políticas sociais e o Estado democrático. Rio de Janeiro: Paz e Terra, 1996. p.11-23.

DRAIBE, S. \& HENRIQUE, W. “'Welfare State', crise e gestão da crise: um balanço da literatura internacional. In: Revista Brasileira de Ciências Sociais, v.3, n.6, p.53-77, fev. 1988.

HARVEY, David. Condição pós-moderna. São Paulo: Loyola: 1993.

NETTO, José Paulo. Capitalismo monopolista e serviço social. São Paulo: Cortez, 1996.

SCHAFF, Adam. A sociedade informática. Săo Paulo: Brasiliense, 1991.

THERBORN, Göran. "A crise e o futuro do capitalismo". In: SADER, E. (org.). Pós-neoliberalismo: as políticas sociais e o Estado democrático. Rio de Janeiro: Paz e Terra, 1996. p.39-61.

Rev. Mediações, Londrina, v. 4, n. 2, p. 51-57, jul./dez. 1999 